\title{
1 Phloem-mediated spreading of SIGS-derived non-coding RNAs in Hordeum vulgare
}

2 Biedenkopf $\mathrm{D}^{1}$, Will $\mathrm{T}^{2}$, Knauer $\mathrm{T}^{3}$, Jelonek $\mathrm{L}^{4}$, Furch $\mathrm{ACU}^{5}$, Busche $\mathrm{T}^{6}$, Koch $\mathrm{A}^{1}$

$3 \quad{ }^{1}$ Institute of Phytopathology, Centre for BioSystems, Land Use and Nutrition, Justus Liebig

4 University, Heinrich-Buff-Ring 26, D-35392, Giessen, Germany

$5 \quad{ }^{2}$ Institute for Resistance Research and Stress Tolerance Julius Kuehn Institute, Federal

6 Research Centre for Cultivated Plants, Erwin-Baur-Straße 27, 06484 Quedlinburg, Germany

$7 \quad{ }^{3}$ Max Planck Institute for Chemical Ecology, Hans-Knoell-Strasse 8, D-07745 Jena, Germany

$8{ }^{4}$ Institute of Bioinformatics and Systems Biology, Justus Liebig University, Heinrich-Buff-

9 Ring 58, D-35392, Giessen, Germany

$10{ }^{5}$ Institute of General Botany and Plant Physiology, Friedrich-Schiller-University, Dornburger

11 Str. 159, 07743 Jena, Germany

$12{ }^{6}$ Centre for Biotechnology - CeBiTec, Bielefeld University, Universitätsstraße 25, D-33615, 13 Bielefeld, Germany

$14 *$ Corresponding author

15 Aline.Koch@agrar.uni-giessen.de

\section{Shorter running title}

17 Phloem-mediated spreading of SIGS-associated RNAs

\section{Highlight}

The use of the SIGS-technology as a biopesticide will require the systemic spreading of dsRNA/siRNA signals. Our findings strongly support the notion of phloem-mediated longdistance movement of SIGS-associated RNAs.

\section{Abstract}

Small (s)RNA molecules are crucial factors in the communication between hosts and their interacting pathogens/pests that can modulate both host defense and microbial virulence/pathogenicity known as cross-kingdom RNA interference (ckRNAi). Consistent with this, sRNAs and their double-stranded (ds)RNA precursors have been adopted to control plant diseases through exogenously applied RNA biopesticides, known as spray-induced gene silencing (SIGS). While RNA spray proved to be effective, the mechanisms underlying the 
transfer and uptake of SIGS-associated RNAs are inadequately understood. Moreover, the use of the SIGS-technology as a biopesticide will require the systemic spreading of dsRNA/siRNA signals. Our results strongly support the notion of phloem-mediated longdistance movement of SIGS-associated dsRNA and/or siRNA. These findings are significant contributions to our mechanistic understanding of RNA spray technology, as our previous data indicate that SIGS requires the processing of dsRNAs by the fungal RNAi machinery. In summary, our findings support the model that SIGS involves: (i) uptake of sprayed dsRNA by the plant (via stomata); (ii) transfer of apoplastic dsRNAs into the symplast (DCL processing into siRNAs); (iii) systemic translocation of siRNA or unprocessed dsRNA via the vascular system (phloem/xylem); (iv) uptake of apoplastic dsRNA or symplastic dsRNA/siRNA depending on the lifestyle/feeding behavior of the pathogen/pest.

\section{Key words}

Aphids; Barley; cross-kingdom RNAi; Fusarium; Phloem; RNAi; RNA spray; RNA-based plant protection; SIGS; stylectomy

\section{Introduction}

The vascular network of higher plants is composed of the phloem and xylem that pervades the whole organism from root to shoot and distributes nutrients and water (van Bel et al. 2011, Lucas et al. 2013). Sieve elements (SEs), companion cells (CCs) and phloem parenchyma cells (PPCs) are the three phloem elements involved in long-distance transport of photoassimilates in angiosperms (van Bel 1996, Hafke et al. 2005). A high density of pore-plasmodesma units (PPUs) and ER coupling between SE and CC underline an intimate symplasmic connection (Kempers et al. 1998, Martens et al. 2006). The cross-walls between the SE-modules become transformed into sieve plates, perforated by plasmodesmata (PD) modified into sieve pores, mediating long-distance transport of signalling molecules that play a pivotal role for the regulation of several developmental processes (Lough and Lucas 2006). This non-cell-autonomous control involves the transfer of informational molecules such as proteins, mRNA and small RNAs (Ham and Lucas 2017). Since the first detection of unspecified nucleic acids in the phloem sap in the late 1990s (Sasaki et al. 1998, RuizMedrano et al. 1999), several studies demonstrated the systemic translocation of mRNA mediating non-cell autonomous control of plant development, defense and nutrient allocation via the phloem (Lough and Lucas 2006, Ham and Lucas 2017). However, decades ago scientists revealed RNA as the agent for systemic acquired gene silencing. They have shown delivery of RNA-based signals via the phloem pathway that affect gene expression at the 
whole-plant level by sequence-specific degradation of targeted mRNA (Jorgensen 1995, Palauqui et al. 1996, 1997). These scientists were the first who linked systemic RNA signaling with a process known as RNA silencing.

RNA silencing (also known as RNA interference, RNAi) is a conserved and integral aspect of gene regulation mediated by small RNAs (sRNAs) that direct gene silencing on the level of transcription but also post-transcriptionally. At the transcriptional level, gene expression is inhibited via RNA-directed DNA methylation (RdDM) while at the post-transcriptional level (PTGS) direct mRNA interference causes inhibition of translation. Originally, RNA silencing is associated with protection against viral infection, control of epigenetic modifications, regulation of genome stability, curbing of transposon movement and regulation of heterochromatin formation (Castel and Martienssen 2013; Koch et al. 2017). Besides its natural function, RNA silencing has emerged as a powerful genetic tool for scientific research over the past several years. It has been utilized not only in fundamental research for the assessment of gene function, but also in various fields of applied research, such as agriculture. In plants, RNA silencing strategies have the potential to protect host plants against predation or infection by pathogens and pests mediated by lethal RNA silencing signals generated in planta (for review see: Koch and Kogel 2014; Yin and Hulbert 2015; Zhang et al., 2017; Qi et al., 2019; Liu et al. 2019). Indeed, our results showed that transgenic Arabidopsis and barley (Hordeum vulgare) plants, expressing a 791 nucleotide (nt) dsRNA (CYP3RNA) targeting all three copies of the CYP51 gene (FgCYP51A, FgCYP51B, FgCYP51C) in Fusarium graminearum $(\mathrm{Fg})$, inhibited fungal infection via a process designated as host-induced gene silencing (HIGS) (Nowara et al. 2010, Koch et al. 2013). Moreover, we demonstrated that HIGS-mediated targeting of the structural sheath protein (Shp) mandatory for aphid feeding, produced significantly lower levels of Shp mRNA compared to aphids feeding on wild-type (wt) plants (Abdellatef et al. 2015).

In addition to the generation of RNA silencing signals in planta, plants can be protected from pathogens and pests by exogenously applied RNA biopesticides (known as spray-induced gene silencing, SIGS) (for review see: Mitter et al. 2017; Cai et al. 2018; Dubrovina and Kiselev 2019; Gaffar and Koch 2019; Dalakouras et al. 2020). Over the last decade, our research (Koch et al., 2013; 2016; 2018; 2019; Höfle et al., 2019, Werner et al., 2019) and the work of others have revealed the enormous potential of RNA-silencing strategies as a potential alternative to conventional pesticides for plant protection, regardless of how targetspecific inhibitory RNAs are applied (i.e. endogenously or exogenously). 
Despite the promising potential of RNAi-based disease control and its benefits for agronomy and the ecosystem, the mechanisms underlying those technologies are virtually unresolved. Understanding the uptake and translocation processes of non-coding RNAs is critical for its successful future application in the field. Application non-coding RNAs as biopesticides will require knowledge on the paths used by dsRNA/siRNA as signal. Previously, we have shown that fluorescent dsRNA is detected in the vascular tissue of barley after spraying the leaves with the $791 \mathrm{nt}$ long CYP3-dsRNA 4488 , directed against fungal CYP51 genes using a detached leaf assay that enabled us to assess fungal growth in distal (semi-systemic, nonsprayed) leaf segments (Koch et al. 2016).

In the present study, we demonstrated that aphids accumulate fluorescent dsRNA, when they feed on distal parts of barley leaves that were sprayed with a Shp-dsRNA. Our study claimed to further prove that sprayed RNAs are systemically translocated via the phloem. Summarizing our results we (i) found spray-induced gene silencing of an aphid mRNA target measured by qRT-PCR, (ii) visualized a fluorescent-labelled dsRNA in the phloem sap of barley using stylectomy (iii) profiled SIGS-derived siRNA in the phloem sap of barley by RNA-Seq analysis (iv) detected SIGS-associated RNAs in barley roots using RT-PCR.

\section{Material and Methods}

\section{Maintenance of plants and aphids}

The spring barley (Hordeum vulgare) cultivar (cv.) Golden Promise (GP) was grown in a climate chamber under $16 \mathrm{~h}$ light photoperiod $\left(240 \mu \mathrm{mol} \mathrm{m} \mathrm{m}^{-2} \mathrm{~s}^{-1}\right.$ photon flux density) at $18^{\circ} \mathrm{C} / 14^{\circ} \mathrm{C}$ (day/night) and $65 \%$ relative humidity. Grain aphids (Sitobion avenae) were reared on three-week-old barley plants in a climate chamber under the same conditions. To obtain synchronized insects, reproductive mature aphids were placed in clip cages (one aphid per cage) on GP plants for $24 \mathrm{~h}$. The adults were then removed, and the offspring were used for experiments as previously described (Gaupels et al., 2008; Schmitz et al., 2012).

\section{dsRNA synthesis}

For spray experiments, the clone p7i-Ubi-Shp-RNAi that includes a partial sequence of the 3,621 bp Shp-cDNA (XM_001943863, ACYPI009881) of the pea aphid Acyrthosiphon pisum $(A p)$ was used as template for the synthesis of 491 nt long Shp-dsRNA (Abdellatef et al., 2015). dsRNA was generated using MEGAscript RNAi Kit (Invitrogen) following MEGAscript $^{\circledR}$ protocols. Primer pairs T7_F and T7_R with T7 promoter sequence at the 5 
end of both forward and reverse primers were designed for amplification of dsRNA (S1 Table).

\section{Spray application of dsRNA}

Second leaves of 2-3-wk-old barley cv. GP were detached and transferred to square petri plates containing $1 \%$ water-agar. The dsRNA was diluted in $500 \mu \mathrm{l}$ water to a final concentration of $20 \mathrm{ng}^{-1} \mathrm{l}^{-1}$. As a control, TRIS/EDTA (TE) buffer was used in a concentration corresponding to final concentration of the dsRNA sample. A typical RNA concentration after elution (see MEGAscript ${ }^{\circledR}$ protocols) was $500 \mathrm{ng} \mu \mathrm{l}^{-1}$ with a final TE buffer concentration of $400 \mu \mathrm{M}$ Tris-HCL and $40 \mu \mathrm{M}$ EDTA. Spraying of leaves was carried out using a spray flask as described (Koch et al., 2016). Each plate containing 10 detached leaves were sprayed in a semi-systemic setup where lower leaf segments were covered with a plastic tray as described (Koch et al., 2016), with either Shp-dsRNA or TE buffer by giving 3-4 puffs, and subsequently kept at room temperature (RT). Forty-eight hours after spraying, aphids were placed on the non-sprayed part of each leaf using clip cages.

For the RNA translocation assays barley seedling were grown in petri dishes for one week. The seedlings were then placed into moist filter paper rolls and grown for 4 days before spraying the first leaf with $20 \mathrm{ng}^{-1} \mathrm{l}^{-1}$ of CYP3RNA or GFP-dsRNA (control). To measure the amount of sprayed dsRNA in different tissues (first leaf, second leaf, shoot and root), samples were taken $24 \mathrm{~h}, 48 \mathrm{~h}$ and $72 \mathrm{~h}$ after spray treatment of the first leaf. To analyse target gene silencing plants were inoculated with $F g$ after spray treatment and samples were taken five days after infection.

\section{Stylectomy and aphid sampling}

At $24 \mathrm{~h}$ after spray application of dsRNA, 20-30 mainly adult aphids (Sitobion avenae) were placed onto the upper surface of each leaf and allowed to feed for $24 \mathrm{~h}$. Following successful cauterization of the mouthparts with a microcautery device (CF-50, Syntech, Fisher and Frame 1984), each aphid stylet exuding phloem sap was marked with two small dots on the leaf surface and kept moist with a drop of DEPC water to prevent early occlusion. After cutting all aphid stylets, the DEPC water droplets were removed with a paper towel and the petri dish was subsequently flooded with silicone oil (M 200, Roth) to prevent evaporation of the sieve tube exudates. Due to the observation of sporadic bacterial and fungal contamination from the leaf surface, a mixture of antimycotic (25 $\mathrm{nl}$ Nystatin $5 \mathrm{mM})$, antibiotic (25 $\mathrm{nl}$ Tetracycline $5 \mathrm{mM}$ ), and 50nl RNAse Inhibtor (Invitrogen) (with traces of Bromophenol Blue 
161 for optical verification) was injected into each sieve tube sap sample at the beginning of the

162 exudation phase to prevent degradation of RNA. By $24 \mathrm{~h}$ later, the sieve tube sap was collected using a microcapillary connected to a small syringe via a silicone tube with a side valve. Depending on the exudation time of the severed stylets, the sample amount reached up to $2 \mu \mathrm{l}$ per stylet over $24 \mathrm{~h}$. The samples of each treatment were pooled and stored at $-80^{\circ} \mathrm{C}$.

\section{Aphid transcript analysis}

To assess silencing of the Shp gene, mRNA expression analysis was performed using quantitative real-time PCR (qRT-PCR). Freshly extracted mRNA from 10 aphids was converted into cDNA using the QuantiTect Reverse Transcription Kit (Qiagen, Hilden, Germany) and $40 \mathrm{ng}$ of cDNA was used as the template for qRT-PCR in an Applied Biosystems 7500 FAST real-time PCR system. Each reaction comprised 7.5 $\mu$ l SYBER Green JumpStart Taq ReadyMix (Sigma-Aldrich, Steinheim, Germany) and 0.5 pmol of the genespecific primers Shp-RNA-qpcr-F1 and Shp-RNA-qpcr-R1 (Table S1). After initial heating to $95^{\circ} \mathrm{C}$ for $5 \mathrm{~min}$, the target was amplified by 40 cycles at $95^{\circ} \mathrm{C}$ for $30 \mathrm{~s}, 52^{\circ} \mathrm{C}$ for $30 \mathrm{~s}$ and $72^{\circ} \mathrm{C}$ for $30 \mathrm{~s}$. Ct values were determined with the 7500 Fast software supplied with the instrument. Levels of Shp transcripts were determined via the $2^{-\Delta \Delta \mathrm{Ct}}$ method (Livak and Schmittgen 2001) by normalizing the amount of target transcript to the amount of the reference transcript 18S ribosomal RNA (GenBank APU27819).

\section{Small RNA library production and sequence analysis}

RNA enriched for the sRNA fraction was purified from plant and fungal samples using the mirVana miRNA Isolation Kit (Life Technologies). Indexed sRNA libraries were constructed from these enriched sRNA fractions with the NEBNext Multiplex Small RNA Library Prep Set for Illumina (New England Biolabs) according to the manufacturer's instructions. Indexed sRNA libraries were pooled and sequenced on the Illumina HiSeq and NextSeq 500 platforms and the sequences sorted into individual datasets based on the unique indices of each sRNA library. The adapters and indices were trimmed with Cutadapt (Martin 2011) version 1.16. Only reads with a length between $19 \mathrm{bp}$ and $30 \mathrm{bp}$ in the first pair of the paired end dataset were analysed. The reads were mapped to the shp-dsRNA vector sequence using bowtie 2 (Langmead and Salzberg 2012) with "-very-sensitive -L 10" to identify sRNAs with a perfect match. The libraries contained 4.1 and 3.5 (control) million reads before trimming and filtering and 0.6 and 0.3 million reads after trimming and filtering. 


\section{Confocal microscopy of fluorophore distribution}

197 Fluorescent labeling of dsRNA was performed using the Atto 488 RNA Labeling Kit (Jena Bioscience, Jena, Germany) following the manufacturer's instructions. Leaves were sprayed in a semi-systemic setup with the labeled dsRNA. Twenty-four $h$ after spraying of fluorescing dsRNA, aphids were placed onto the leaves and allowed to feed overnight. Twenty-four $h$ after infestation only stylets of the non-sprayed leaf area were cut. Phloem droplets that appeared on the stylet tips were imaged using a Leica TCS SP2 (Leica Microsystems, Wetzlar, Germany) equipped with a 75-mW argon/krypton laser (Omnichrome, Chino, CA) and a water immersion objective (HCX APO L40x0.80 W U-V-1 objective).

\section{Results}

\section{SIGS-mediated gene silencing in Sitobion avenae fed on barley leaves}

Mobile cell non-autonomous inhibitory RNAs that spread gene silencing into adjacent cells and tissues have been shown to move through the vascular system (Lewsey et al., 2016, Palauqui et al., 1997, Zhang et al., 2016). Previously, we demonstrated that aphids which fed on transgenic barley expressing dsRNA derived from the Shp gene (Shp-dsRNA), produce significantly lower levels of Shp mRNA compared to aphids feeding on wild-type (wt) plants (Abdellatef et al., 2015). Based on these previous data, we modified the setup for dsRNA application in order to demonstrate a semi-systemic transfer of the dsRNA. Therefore, we tested whether locally sprayed $491 \mathrm{nt}$ long Shp-dsRNA confers gene silencing in grain aphids feeding from distal, non-sprayed segments of the same barley leaves. To this end, the upper part of detached leaves (local tissue) was sprayed with $20 \mathrm{ng} \mathrm{LL}^{-1} \mathrm{Shp}$-dsRNA, while the lower part (distal tissue) was covered by a plastic tray to prevent direct dsRNA contact. After $48 \mathrm{~h}$, we placed aphids at the distal, non-sprayed part of the leaves in clip cages and led them feed on the phloem for $24 \mathrm{~h}$. Subsequently aphids were harvested and assessed for downregulation of the Shp target gene expression using qRT-PCR. The relative expression level of the aphid's Shp gene was reduced by almost $60 \%$ compared to aphids that fed on control leaves sprayed with Tris-EDTA (TE) buffer (Fig. 1), suggesting that the transfer of inhibitory RNA from the plant phloem sap to the insect was successful. 
227 Encouraged by the RNAi effects on the Shp target gene in phloem-sucking S. avenae, we

228 investigate whether the sprayed Shp-dsRNA is translocated in the phloem and/or processed by

229 the plant's silencing machinery. To this end, we used aphid stylectomy to gain access to pure

230 phloem sap of barley leaves (Fig. 2 A-C). Stylectomy is commonly used to study a broad

231

232

233

234

235

236

237

238

239

240

241

242

243

244

245

246

247

248

249

250

251

252

253

254

255

256

257

258

259

260 variety of physiological, mechanical and molecular properties of the plant phloem (Turgeon and Wolf 2009; Peel 1975; Thompson and van Bel 2012).

To further visualize the phloem-mediated transfer of sprayed Shp-dsRNA, it was labeled with the green fluorescent dye ATTO 488 (Shp-dsRNA ${ }_{\mathrm{A} 488}$ ) and sprayed onto barley leaves using the semi-systemic setup followed by stylectomy with $S$. avenae in the distal, non-sprayed leaf parts. Using confocal laser scanning microscopy, a green fluorescent signal was detected $24 \mathrm{~h}$ after feeding (48 $\mathrm{h}$ after spraying) and cutting at the stylet tip (Fig. $2 \mathrm{D}$ ). Together these data show that sprayed Shp-dsRNA is transferred via the plant's phloem.

\section{RNA-Seq profiling of stylectomy samples revealed SIGS-derived siRNAs}

We addressed the question whether the phloem-transferred Shp-dsRNA is stable during transport or alternatively at least partially processed into small interfering RNAs. To test this possibility, we profiled Shp-dsRNA-derived siRNAs in the phloem sap after isolation using stylectomy. Small RNA sequencing (sRNAseq) analysis revealed Shp-dsRNA-derived siRNA in distal (non-sprayed) leaf segments (Fig. 3). These data suggest that Shp-dsRNA-derived siRNAs also are processed by the plant's silencing machinery and systemically transferred via the phloem.

\section{Translocation of sprayed dsRNA from leaves to barley roots}

The RNA silencing signal can travel over long distances and trigger silencing in distant plant tissues (Molnar et al., 2010, Lewsey et al., 2016). However, little is known about how SIGSderived dsRNAs and/or siRNAs are transported in the plant. To test whether there is wider systemic spreading of RNA silencing signals via the phloem and to further determine to what extend those sprayed RNAs are translocated within the plant we analysed the spreading of the sprayed dsRNA within intact barley plants. Towards this, we measured the amount of sprayed RNA in leaves, shoots and roots at different timepoints after spray application using qRTPCR. To assess transport of sprayed dsRNA in systemic, non-sprayed plant tissue we used two-week old barley plants that were grown in filter paper. For the systemic setup, the plants were covered before spraying with a plastic tray leaving only the upper part/leaf tip (approximately $1 \mathrm{~cm}$ ) of the first leaf uncovered. Using this approach we found that the 
261 CYP3RNA translocate from the first (sprayed) leaf into the second leaf as well as the shoot

262 tissue over time (Fig. 4), the amount of sprayed dsRNA decreased from $1 \mathrm{~d}$ to $3 \mathrm{~d}$ after spray

263 (das) application in leaves and shoots. Interestingly, the amount of dsRNA within the roots

264 increased from 1 das to 3 das (Fig. 5), indicating a translocation route from leaves to roots.

265 However, to test whether the amount of transferred, SIGS-derived RNAs is sufficient to

266 provoke target gene silencing, we inoculated the plants with $F g$ and measured the transcript

267 level of FgCYP51 target genes in leaves, shoots and roots of infected plants (Fig. 6). Notably,

268 we measured the strongest target gene silencing in the first leaf, the leaf that was spray

269 treated. However, the second leaf samples exhibited an overall target gene silencing of $80 \%$,

270 which is still very high. In the analysed shoot and root tissue we found $50 \%$ silencing of the

271 fungal CYP51 target genes. Together these data are consistent with our translocation

272 observations, indicating that the transferred SIGS-associated RNAs can provoke silencing of

273 their complementary target genes. Moreover, we found that $7 \mathrm{~d}$ after infection hypocotyls of

274 plants sprayed with CYP3RNA developed less brownish lesions compared to TE-treated

275 control plants suggesting that the amount of transferred RNA has the potential to prevent

276 plants from $\mathrm{Fg}$ infection (Fig. 7). 


\section{Discussion}

RNA sprays may provide an alternative strategy to avoid chemical pesticides and genetically modified crops for combating agricultural pests. However, systemic translocation of sprayed RNA biopesticides is critical for its successful future application in the field. To prove phloem-mediated transport of SIGS-associated RNAs we decided to transfer a HIGS approach established for a phloem-sap sucking grain aphid Sitobion avenae (Abdellatef et al., 2015) to a SIGS proof-of-concept study. To investigate uptake and transport of sprayed dsRNA, we tested whether locally sprayed Shp-dsRNA confers gene silencing in $S$. avenae infecting distal, non-sprayed segments of barley leaves. To this end, we assessed whether the phloemtransported inhibitory RNA affect Shp target gene expression in aphids fed on the dsRNAsprayed barley leaves using qRT-PCR. The relative expression level of the aphid's Shp gene was reduced by almost $60 \%$ compared to aphids that fed on buffer-sprayed controls (Fig. 1), suggesting that the transfer of inhibitory RNA from the plant phloem sap to the insect was successful. Next, we conducted another experiment to investigate whether the spray-applied Shp-dsRNA is translocated in the phloem and/or processed by the plant's silencing machinery. Specifically, we used aphid stylectomy, a widely used technique to study physiological, mechanical and molecular properties of the plant phloem (Turgeon and Wolf 2009; Peel 1975; Thompson and Van Bel 2012). Here, we used this technique to gain access to the phloem sap of barley leaves (Fig. 2). To further explore the phloem-mediated transfer of sprayed Shp-dsRNA, we sprayed fluorescent labelled Shp-dsRNA $\mathrm{A}_{488}$ onto barley leaves using a systemic experimental design (Koch et al., 2016) following phloem sampling by stylectomy at the distal, non-sprayed leaf parts. Using CLSM, we detected a green fluorescent signal after cutting off the stylet tip of feeding aphids (Fig. 2 D). These results are consistent with our previous detection of the unprocessed $791 \mathrm{nt}$ precursor CYP3RNA in both local and distal tissue using northern blot analysis, showing that the long dsRNA is systemically translocated within the plant (Koch et al., 2016). Moreover, investigation of longitudinal leaf sections revealed that the fluorescence was not confined to the apoplast but also was present in the symplast of phloem parenchyma cells, companion cells, and mesophyll cells, as well as

320 in trichomes and stomata (Koch et al., 2016). Supportively, apoplastic movement of RNA has been proposed, e.g. to explain how maternally expressed siRNAs could be transferred from the endosperm of developing seeds into the symplastically isolated embryo (Martienssen 
2010). However, the mechanism by which the sprayed RNA overcomes the apoplasticsypmastic barrier is yet unknown.

Despite of the translocation of dsRNA, we found that also CYP3RNA-derived $21 \mathrm{nt}$ and $22 \mathrm{nt}$ siRNAs accumulated in the distal leaf segments, demonstrating that CYP3RNA was partly processed by the plant (Koch et al., 2016). Therefore, we predict that SIGS-derived siRNAs would also translocate via the barley phloem. To test this possibility, we additionally profiled Shp-dsRNA-derived siRNAs using stylectomy. Small RNA-sequencing analysis revealed Shp-dsRNA-derived siRNA in distal (non-sprayed) leaf segments (Fig. 3). These data suggest that Shp-dsRNA-derived siRNAs also are processed by the plant's silencing machinery and are systemically transferred via the phloem. Importantly, we have previously shown that, when CYP3RNA ${ }_{4488}$-sprayed leaves were inoculated with $F g$ the fluorescent signal was also detectable inside fungal conidia, germtubes, and fungal mycelium (Koch et al., 2016). In addition or as an alternative to plant-mediated gene silencing in the fungus, systemic translocation within the plant and accumulation by the fungus could also mediate direct processing of CYP3RNA by the fungus' gene silencing machinery to target fungal CYP51 genes. This finding that unprocessed long dsRNA is absorbed from leaf tissue has important implications for future disease control strategies based on dsRNA. It is very likely that application of longer dsRNAs might be more efficient than application of siRNAs given their more efficient translocation. Moreover, in contrast to using only one specific siRNA, processing of long dsRNA into many different inhibitory siRNAs by the fungus may reduce the chance of pathogen resistance under field test conditions.

Consistent with our findings, there are several studies showing that mobile cell nonautonomous inhibitory RNAs that spread gene silencing into adjacent cells and tissues move through the vascular system (Lewsey et al., 2016, Palauqui et al., 1997). Grafting experiments revealed that siRNAs are detectable in tissues of DCL mutants that are defective for siRNA biogenesis (Molnar et al., 2010). This led to the speculation that siRNAs and not their long dsRNA precursors are the mobile silencing signals (Dunoyer et al., 2013). However, until now the exact molecular forms of mobile RNAs remain unclear (Parent et al., 2012). Here we showed movement of sprayed dsRNA from barley leaves over stems to the root tissue within three days after spray treatment (Fig. 4). Moreover, we found that the transferred SIGS-associated RNAs confer target gene silencing in the respective tissues as well as $F g$ disease resistance (Fig. 7, Koch et al., 2019). Interestingly, we measured the highest silencing efficiency in the tissue that was either directly sprayed or near to the sprayed locus. In other words, it seemed that the amount and/or the nature of the mobile 
357 RNA determine the systemic silencing efficiency. Therefore, we predict a dilution effect that 358 correlate with the distance to the initial spray site (or tissue). This is consistent with another 359 study, where the authors confirmed the spreading of dsRNA from local to systemic tissue by 360 one hour after rub-inoculation of dsRNA using semi-quantitative RT-PCR. Moreover, they 361 showed that dsRNA levels continuously decreased in the local (treated) tissue from 3 dpi to 9 362 dpi where dsRNA was no longer detectable (Mitter et al., 2017). More recently, Kaldis et al. 363 (2018) showed that exogenously applied dsRNA derived from the silencing suppressor HC364 Pro and the coat protein genes of zucchini yellow mosaic virus (ZYMV) protect watermelon 365 and cucumber against ZYMV and spread systemically over long distances in cucurbits 366 (Kaldis et al., 2018).

367 In summary, our data suggest that sprayed dsRNAs are taken up by the plant, spread 368 systemically via the plant vascular system, and are partially processed into siRNAs by the 369 plant's gene silencing machinery (Fig. 8). As our results strongly support the notion of 370 phloem-mediated long-distance movement of SIGS-associated dsRNA and/or siRNA, further 371 research is needed to address central questions as: How are dsRNA transported at the 372 apoplast-symplast interface? How does the fungus take up SIGS-associated RNAs from the 373 apoplast and/or the symplast? 


\section{Acknowledgment}

We thank C. Birkenstock, U. Schnepp and V. Weisel for excellent plant cultivation. We also thank Dr. Jens Steinbrenner for assisting in microscopic analyses. This work was supported by the Deutsche Forschungsgemeinschaft, Research Training Group (RTG) 2355 (project number 325443116$)$ to $\mathrm{AK}$.

\section{References}

396

397

398

399

400

401

402

403

404

405

Abdellatef E, Will T, Koch A, Imani J, Vilcinskas A, Kogel KH. 2015. Silencing the expression of the salivary sheath protein causes transgenerational feeding suppression in the aphid Sitobion avenae. Plant Biotechnology Journal 13, 849-857.

Bolger AM, Lohse M, Usadel B. 2014. Trimmomatic: A flexible trimmer for Illumina Sequence Data. Bioinformatics 30, 2114-2120.

Cai Q, He B, Kogel KH, Jin H. 2018. Cross-kingdom RNA trafficking and environmental RNAi - nature's blueprint for modern crop protection strategies. Current Opinion Microbiology, 46, 58-64.

Castel SE, Martienssen RA. 2013. RNA interference in the nucleus: roles for small RNAs in transcription, epigenetics and beyond. Nature Review Genetics 14,100-112.

Dalakouras A, Wassenegger M, Dadami E, Ganopoulos I, Pappas ML, Papadopoulou K. 2020. Genetically Modifed Organism-Free RNA Interference: Exogenous. Plant Physiology, 182.

Dubrovina AS, Kiselev KV. 2019. Exogenous RNAs for Gene Regulation and Plant Resistance. International Journal of Molecular Sciences, 20(9), 2282

Dunoyer P, Melnyk C, Molnar A, Slotkin RK. 2013. Plant Mobile Small RNAs. Cold Spring Harbor Perspectives in Biology 5, 017897.

Fisher DB, Frame JM. 1984. A guide to the use of the exuding-stylet technique in phloem physiology. Planta 161, 385-393.

Gaffar F, Imani J, Karlovsky JP, Koch A and Kogel KH. 2019 Various components of the RNAi pathway are required for conidiation, ascosporogenesis, virulence, DON production and SIGS-mediated fungal inhibition by exogenous dsRNA in the Head Blight pathogen Fusarium graminearum. Frontiers in Microbiology, doi.org/10.3389/fmicb.2019.01662

Gaffar FY, Koch A. 2019. Catch me if you can! RNA silencing-based improvement of antiviral plant immunity. Viruses 11, 673. 
421 Gaupels F, Buhtz A, Knauer T, Deshmukh S, Waller F, van Bel AJE, Kogel KH and

422 Kehr J. 2008. Adaptation of aphid stylectomy for analyses of proteins and mRNAs in barley 423 phloem sap. Journal of Experimental Botany 59, 3297-3306.

424 Hafke JB, van Amerongen J-K, Kelling F, Furch ACU, Gaupels F, van Bel AJE. 2005.

425 Thermodynamic battle for photosynthate acquisition between sieve tubes and adjoining 426 parenchyma in transport phloem. Plant Physiology 138, 1527-1537.

427 Ham BK, Lucas WJ. 2017. Phloem-Mobile RNAs as Systemic Signaling Agents. Annual 428 Review Plant Biology 28, 173-195.

Höfle L, Shrestha A, Werner BT, Jelonek L, Koch A. 2019. Study on the efficacy of dsRNAs with increasing length targeting Fusarium graminearum CYP51 genes comparing HIGS and SIGS approaches. RNA Biology. accepted.

Jorgensen RA. 1995. Cosuppression, flower color patterns, and metastable gene expression states. Science 268, 686-691

Kaldis A, Berbati M, Melita O, Reppa C, Holeva M, Otten P, Voloudakis A. 2018. 435 Exogenously applied dsRNA molecules deriving from the Zucchini yellow mosaic virus 436 (ZYMV) genome move systemically and protect cucurbits against ZYMV. Molecular Plant 437 Pathology 19, 883-895.

Kempers R, Ammerlaan A, van Bel AJE. 1998. Symplasmic constriction and ultrastructural features of the sieve element/companion cell complex in the transport phloem of apoplasmically and symplasmically phloem-loading species. Plant Physiology 116, 271-278.

Koch A, Biedenkopf D, Furch ACU, et al., 2016. An RNAi-based control of Fusarium graminearum infections through spraying of long dsRNAs involves a plant passage and is controlled by the fungal silencing machinery. Plos Pathogens 12, e1005901.

444 Koch A, Höfle L, Werner BT, Imani J, Schmidt A, Jelonek L, Kogel KH. 2019. SIGS vs 445 HIGS: A study on the efficacy of two dsRNA delivery strategies to silence Fusarium $446 \mathrm{FgCYP51}$ genes in infected host and non-host plants. Molecular Plant Pathology. doi: $447 \quad 10.1111 / \mathrm{mpp} .12866$

448 Koch A, Kang HG, Steinbrenner J, Dempsey DA, Klessig DF, Kogel KH. 2017. MORC 449 Proteins: Novel Players in Plant and Animal Health. Frontiers in Plant Science 18, 1720.

450 Koch A, Kogel KH 2014. New wind in the sails: improving the agronomic value of crop 451 plants through RNAi-mediated gene silencing. Plant Biotechnology Journal 12, 821-831.

Koch A, Kumar N, Weber L, Keller H, Imani J, Kogel KH 2013. Host-induced gene silencing of cytochrome P450 lanosterol C14 $\alpha$-demethylase-encoding genes confers strong resistance to Fusarium spec. Proceedings of the National Academy of Sciences of the United States of America 110, 19324-19329.

456 Koch A, Stein E, Kogel KH. 2018 RNA-Based Disease Control as a Complementary 457 Measure to Fight Fusarium Fungi Through Silencing of the Azole Target Cytochrome P450 458 Lanosterol C-14 $\alpha$-Demethylase. European Journal of Plant Pathology.

459 Konakalla NC, Kaldis A, Berbati M, Masarapu H, Voloudakis AE. 2016. Exogenous 460 application of double-stranded RNA molecules from TMV p126 and CP genes confers 461 resistance against TMV in tobacco. Planta 244, 961-969.

462 Langmead B, Salzberg S. 2012. Fast gapped-read alignment with Bowtie 2. Nature Methods 463 9, 357-359. 
464 Lewsey MG, Hardcastle TJ, Melnyk CW, Molnar A, Valli A, Urich MA, Nery JR, 465 Baulcombe DC, Ecker JR. 2016. Mobile small RNAs regulate genome-wide DNA 466 methylation. Proceedings of the National Academy of Sciences of the United States of 467 America 113, 801-810. Livak KJ, Schmittgen TD. 2001. Analysis of relative gene expression data using real-time quantitative PCR and the 2(-Delta C(T)) Method. Methods (San Diego, Calif.) 25, 402-408.

Lough TJ, Lucas W. 2006. Integrative plant biology: role of phloem long-distance macromolecular trafficking. Annual Review Plant Biology 57, 203-232.

Lucas WJ, Groover A, Lichtenberger R, et al., 2013. The plant vascular system: evolution, development and functions. Journal of Integrative Plant Biology 55, 294-388.

Martens HJ, Roberts AG, Oparka KJ, Schulz A. 2006. Quantification of plasmodesmatal endoplasmic reticulum coupling between sieve elements and companion cells using fluorescence redistribution after photobleaching. Plant Physiology 142, 471-480.

Martin M. 2011. Cutadapt removes adapter sequences from high-throughput sequencing reads. EMBnet.journal, 17, 10-12.

Mitter N, Worrall EA, Robinson KE, et al., 2017. Clay nanosheets for topical delivery of RNAi for sustained protection against plant viruses. Nature plants 3, 16207. 2010. Small silencing RNAs in plants are mobile and direct epigenetic modification in recipient cells. Science 328, 872-875.

Palauqui JC, Elmayan T, De Borne FD, Crete P, Charles C, Vaucheret H. 1996. Frequencies, timing, and spatial patterns of co-suppression of nitrate reductase and nitrite reductase in transgenic tobacco plants. Plant Physiology 112, 1447-1456.

Palauqui JC, Elmayan T, Pollien JM, Vaucheret H. 1997. Systemic acquired silencing: transgene-specific posttranscriptional silencing is transmitted by grafting from silenced stocks to non-silenced scions. EMBO Journal 16, 4738-4745.

Parent JS, Martínez de Alba AE, Vaucheret H. 2012. The origin and effect of small RNA signaling in plants. Frontiers in Plant Science 9, 179.

Peel AJ. 1975. Investigations with aphid stylets into the physiology of the sieve tube. In Transport in Plants 1 Phloem Transport. Volume 1st edition. Edited by Zimmerman MH, Milburn JA. Berlin Heidelberg New York: Springer; 171-195. of mNACP mRNA: implications for supracellular regulation in plants. Development 126, 4405-4419.

501 The cellular immune responses of the pea aphid to foreign intrusion and symbiotic challenge. 502 Plos One 7. e42114.

503 Thompson GA, Van Bel AJE. 2012. Phloem: Molecular cell biology, systemic

504

Sasaki T, Chino M, Hayashi H, Fujiwara T 1998. Detection of several mRNA species in rice phloem sap. Plant and Cell Physiology 39, 895-897.

Schmitz A, Anselme C, Ravallec M, Rebuf C, Simon JC, Gatti JL and Poirié M. 2012. communication, biotic interactions. Wiley-Blackwell: Oxford, UK. 
505 Turgeon R, Wolf S. 2009. Phloem transport: Cellular pathways and molecular trafficking. 506 Annual Review Plant Biology 60, 207-221.

507 van Bel AJE, Furch ACU, Hafke JB, Knoblauch M, Patrick JW. 2011. (Questions) on 508 phloem biology. 2. Mass flow, molecular hopping, distribution patterns and macromolecular 509 signalling. Plant Science 181, 325-330.

510 van Bel AJE. 1996. Interaction between sieve element and companion cell and the 511 consequences for photoassimilate distribution. Two structural hardware frames with 512 associated physiological software packages in dicotyledons? Journal of Experimental Botany 513 47, 1129-1140.

514 Wang M, Weiberg A, Lin FM, Thomma BP, Huang HD, Jin H. 2016. Bidirectional cross515 kingdom RNAi and fungal uptake of external RNAs confer plant protection. Nature Plants 2, 51616151.

517 Yin C, Hulbert S. 2015. Host Induced Gene Silencing (HIGS), a Promising Strategy for 518 Developing Disease Resistant Crops. Gene Technology 4, 130.

519 Zhang J, Khan SA, Heckel DG, Bock R. 2017. Next-Generation Insect-Resistant Plants: 520 RNAi-Mediated Crop Protection. Trends in Biotechnology 35, 871-882. 


\section{Figure legends}

552

Figure 1: Silencing of Shp gene in Sitobion avenae that fed on dsRNA sprayed barley leaves.

554 Gene-specific expression of Shp was measured by qRT-PCR and normalized to aphid 18S 555 ribosomal RNA (GenBank APU27819) as reference gene. cDNA was generated after total 556 RNA extraction from aphids at 5 days of inoculation after dsRNA spray. The reduction in Shp 557 gene expression in the aphids that fed on Shp-dsRNA sprayed leaves compared to the mock sprayed control was statistically significant. Error bars represent SE of three independent experiments each using 5-10 adult aphids for each treatment $(* * p<0.01$; students t-test).

Figure 2: Stylectomy. (A) Sitobion avenae feeding on a barley leaf shortly before cutting the mouthparts (stylet) with a tungsten needle connected to a microcautery device. (B) Injection of antimycotic, antibiotic and RNAse-inhibitor using a microcapillary at the beginning of the exudation period after overlaying with silicone oil. (C) Sampling of sieve-tube exudate from a cut aphid stylet under silicone oil with a microcapillary after an exudation period of 24 hours. (D) Stylectomy of ATTO 488-labeled Shp-dsRNA 4488 in sprayed barley leaves. Detection of Shp-dsRNA $A_{A 48}$ (green) in the phloem sap droplet using stylectomy. Aphids were placed on non-sprayed leaf parts and stylectomy was performed 48 hours after spray treatment with Shp-dsRNA $A_{A 488}$

571 Figure 3: Profiling of Shp-dsRNA-derived siRNAs in the phloem sap from barley leaves. 572 Phloem sap was sampled by stylectomy. Total RNAs were isolated using a single cell RNA 573 purification kit (Norgen Biotek Corp.). sRNA reads between 19 and $30 \mathrm{nt}$ from Shp-dsRNA- 
574 sprayed and mock-treated barley leaves were mapped to Shp-dsRNA precursor (Abdellatef et 575 al., 2015). Read coverage varied from 0-162 as indicated. Sequencing data are gained from 5 576 pooled separate phloem sap isolations experiments with a total sample amount of $10 \mu \mathrm{l}$ 577 phloem sap from sprayed leaves and $10 \mu 1$ phloem sap from non-sprayed leaves, respectively.

579 Figure 4: Detection of CYP3RNA in barley leaves and shoots at different time points after spray application. Amount of CYP3RNA in the first (sprayed) leaf as well as non-sprayed second leaves and shoot tissue. The relative amount of sprayed CYP3RNA measured by qPCR decreased over time in leaves and increased in roots compared to mock-sprayed control leaves. Bars represent mean values \pm SEs of three independent experiments. The reduction of CYP3RNA vs. mock-sprayed leaves was statistically significant ( $\mathrm{P}<0.05$; Student's t-test).

Figure 5: Detection of CYP3RNA in barley roots at different time points after spray application. Amount of CYP3RNA in the roots of barley plants $24 \mathrm{~h}, 48 \mathrm{~h}$ and $72 \mathrm{~h}$ after spray treatment, respectively. The relative amount of sprayed CYP3RNA measured by qPCR decreased over time in leaves and increased in roots compared to mock-sprayed control leaves. Bars represent mean values \pm SEs of three independent experiments. The reduction of CYP3RNA vs. mock-sprayed leaves was statistically significant ( $\mathrm{P}<0.05$; Student's t-test).

Figure 6: Gene-specific qPCR analysis of fungal CYP51A, CYP51B, and CYP51C transcripts at $6 \mathrm{dpi}$ (corresponding to $9 \mathrm{~d}$ after spraying). The reduction in fungal CYP51 gene expression on CYP3-dsRNA-sprayed leaves as compared with GFP-dsRNA-sprayed controls was statistically significant $(* \mathrm{P}<0.05, * * \mathrm{P}<0.01, * * * \mathrm{P}<0.001$; Student's t test).

Figure 7: SIGS-mediated control of $F g$ on barley plants sprayed with CYP3RNA. (A) Twoweek-old barley plants cv. Golden Promise were sprayed with CYP3RNA $\left(20 \mathrm{ng} \mu \mathrm{L}^{-1}\right)$ or

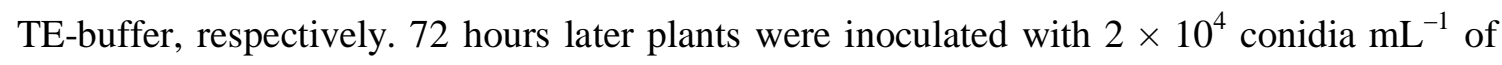

$601 \mathrm{Fg} .7 \mathrm{~d}$ after infection hypocotyls of plants sprayed with CYP3RNA developed less brownish 602 lesions compared to TE-treated control plants. 
604 Figure 8: The molecular mechanism of SIGS is controlled by the fungal silencing machinery.

605 In summary, our findings support the model that SIGS involves: (1) uptake of sprayed dsRNA 606 by the plant (via stomata); (2) transfer of apoplastic dsRNAs into the symplast (DCL 607 processing into siRNAs); (3) systemic translocation of siRNA or unprocessed dsRNA via the 608 vascular system (phloem/xylem); (4) uptake of apoplastic dsRNA (a) or symplastic 609 dsRNA/siRNA by the fungus (b); (5) processing into siRNA by fungal DCLs (Koch et al., 610 2016, Gaffar et al., 2019).

611

612

613

614

615

616

617

618

619

620

621

622

623

624

625

626

627

628

629 
630

631

632

633

634

635

636

637 Figure 1

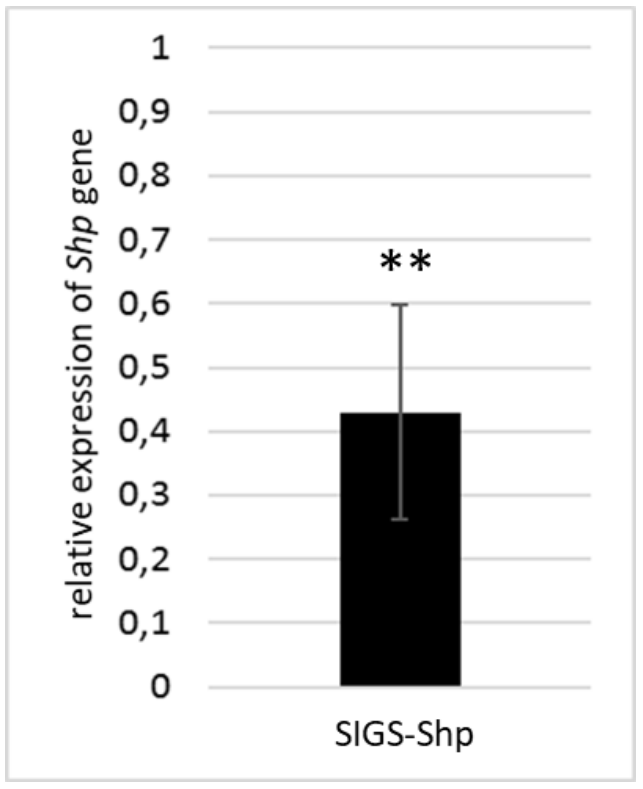

639

640

641

642

643

644

645

646

647

648

649

650 
bioRxiv preprint doi: https://doi.org/10.1101/2019.12.30.891002; this version posted December 30, 2019. The copyright holder for this preprint (which was not certified by peer review) is the author/funder. All rights reserved. No reuse allowed without permission.

651

652

653

654

655

656

657

658

659

$660 \quad$ Figure 2

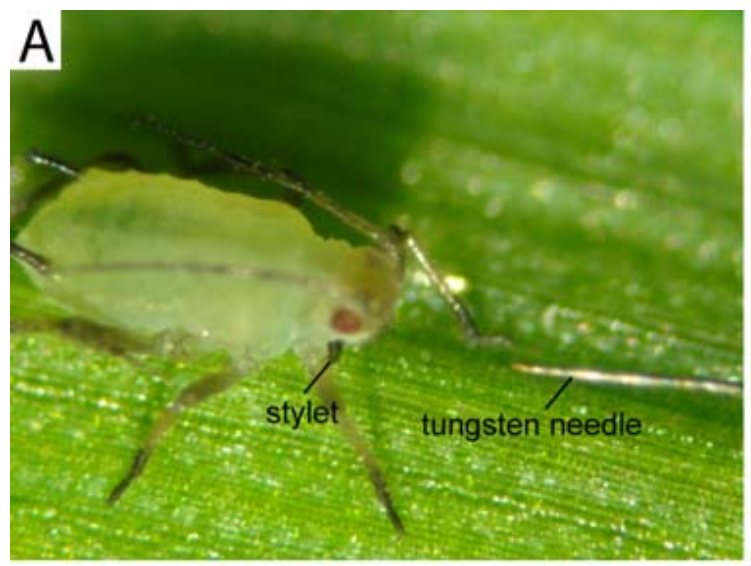

B

C

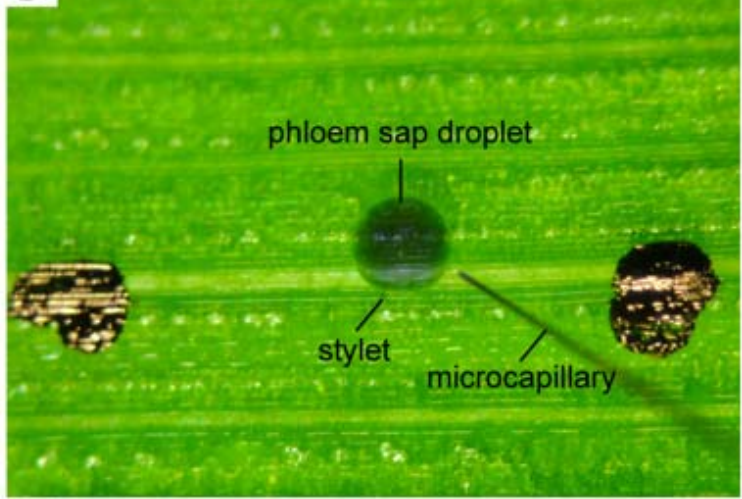

661

D

microcapillary

with phloem sap

662

663

664

665

666

667 
bioRxiv preprint doi: https://doi.org/10.1101/2019.12.30.891002; this version posted December 30, 2019. The copyright holder for this preprint (which was not certified by peer review) is the author/funder. All rights reserved. No reuse allowed without permission.

669

670

671

672

673

674

675

676

677

678

Figure 3

679

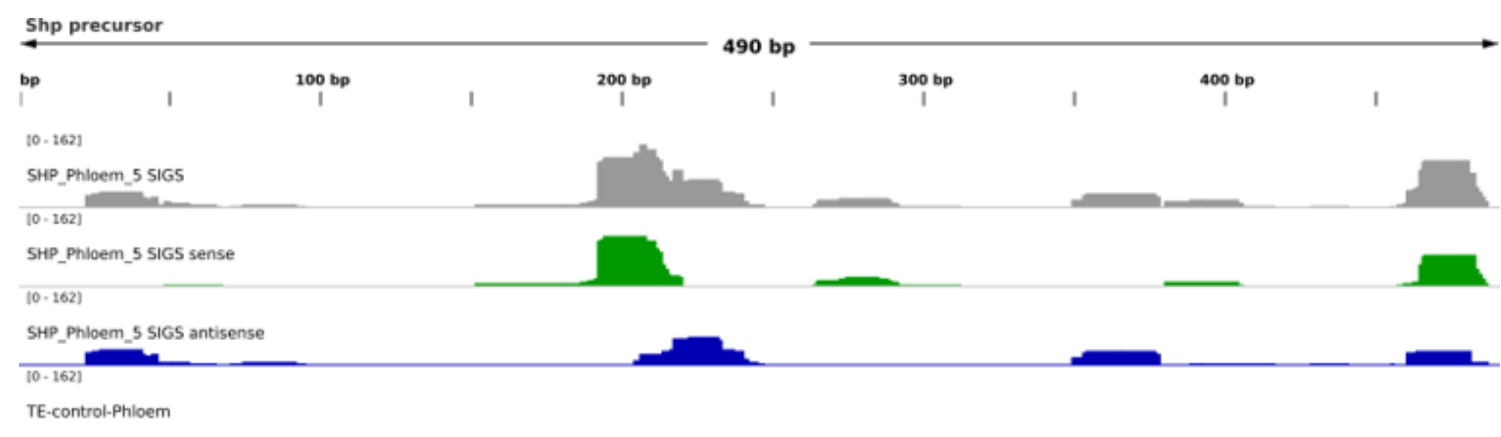

$10-162]$

TE.control.Phioem sense

(10-162)

TE-control-Phioem antisense

681

682

683

684

685

686

687

688

689

690

691

692

693 
694

695

696

697

698

699

700

701

702

703

Figure 4

704

705

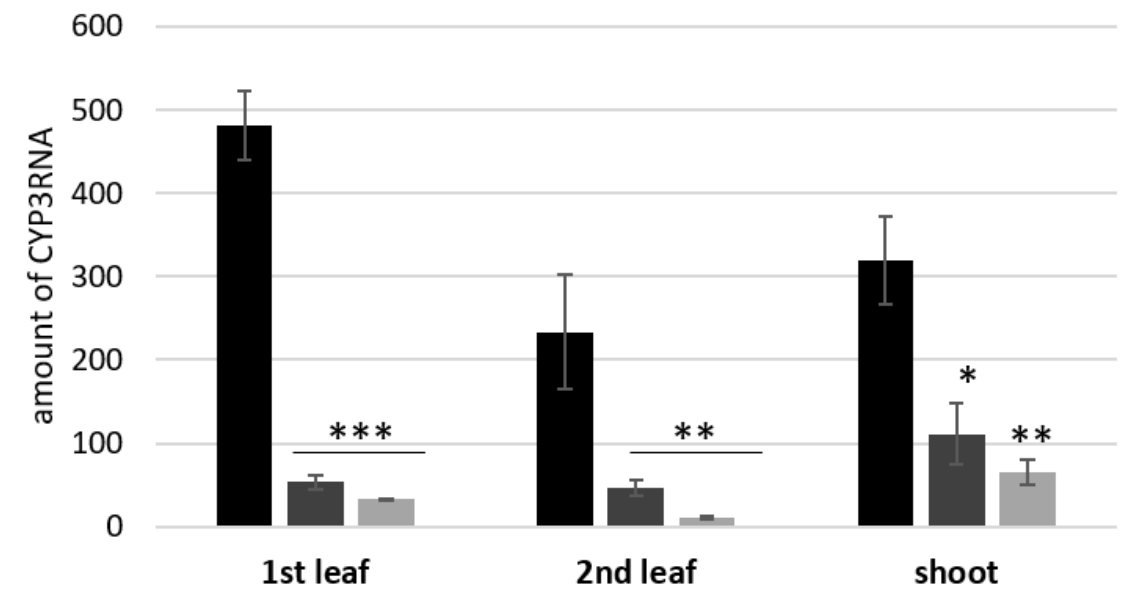

706

707

708

709

710

711

712

713

714

715

716

717 
bioRxiv preprint doi: https://doi.org/10.1101/2019.12.30.891002; this version posted December 30, 2019. The copyright holder for this preprint (which was not certified by peer review) is the author/funder. All rights reserved. No reuse allowed without permission.

718

719

720

721

722

723

724

725

726

727

Figure 5

728

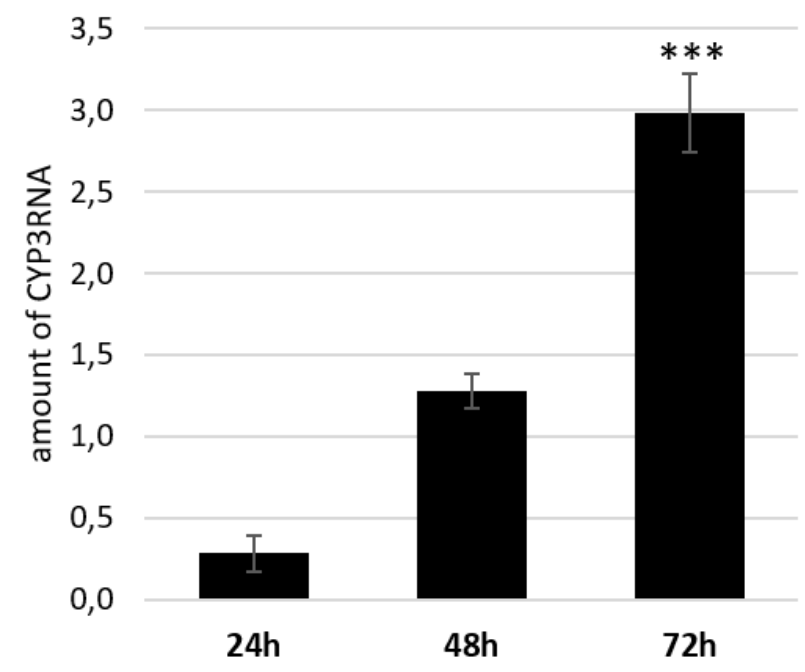

729

730

731

732

733

734

735

736

737

738

739

740 
Figure 6

751

752

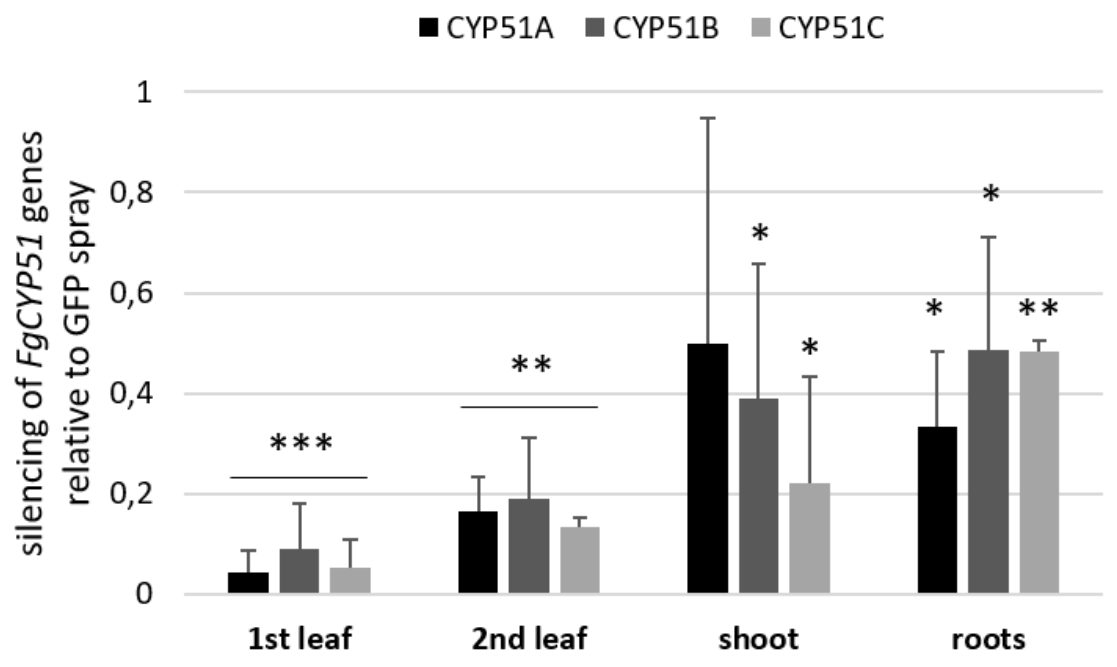

753

754

755

756

757

758

759

760

761 
bioRxiv preprint doi: https://doi.org/10.1101/2019.12.30.891002; this version posted December 30, 2019. The copyright holder for this preprint (which was not certified by peer review) is the author/funder. All rights reserved. No reuse allowed without permission.

763

764

765

766

767

768

769

770

771

772

Figure 7

773
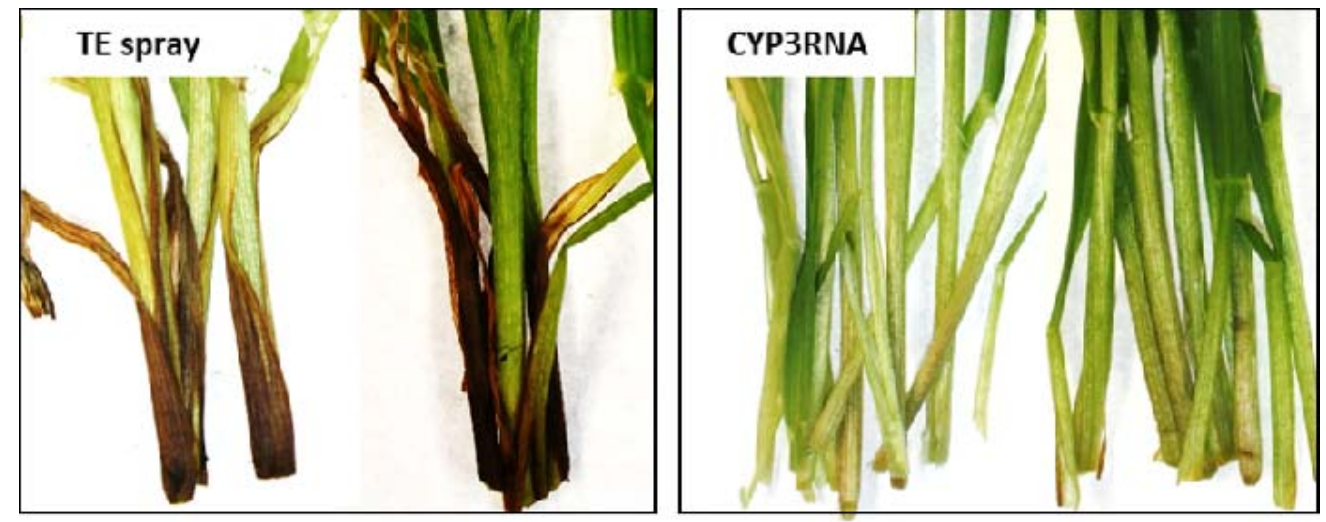

774

775

776

777

778

779

780

781

782

783

784

785 
Figure 8

797

\section{Spray-induced gene silencing}

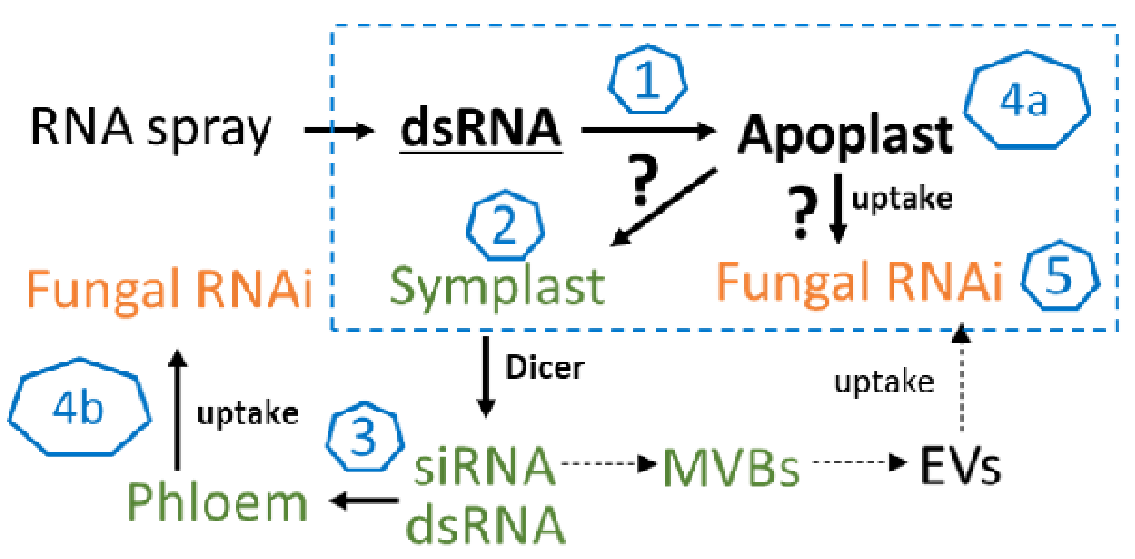




\section{Spray-induced gene silencing}

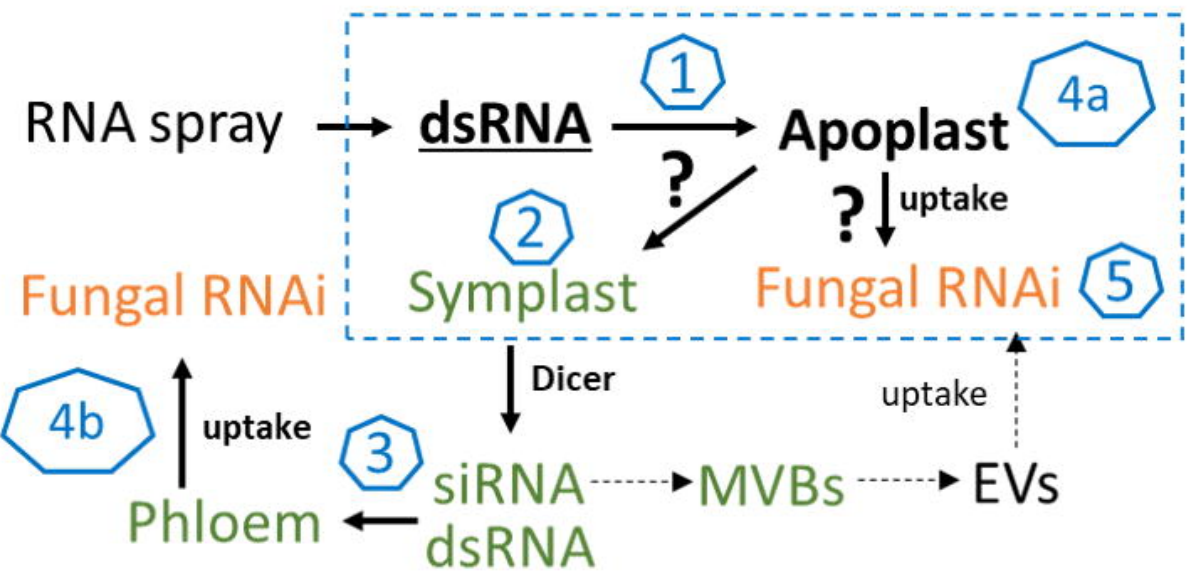




\section{TE spray}

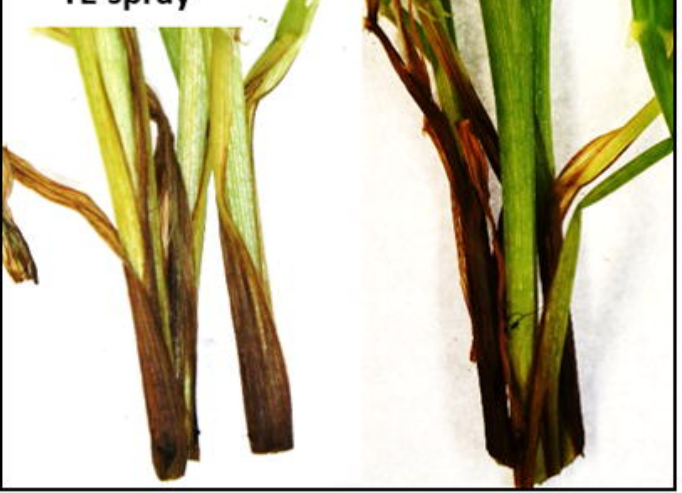

CYP3RNA

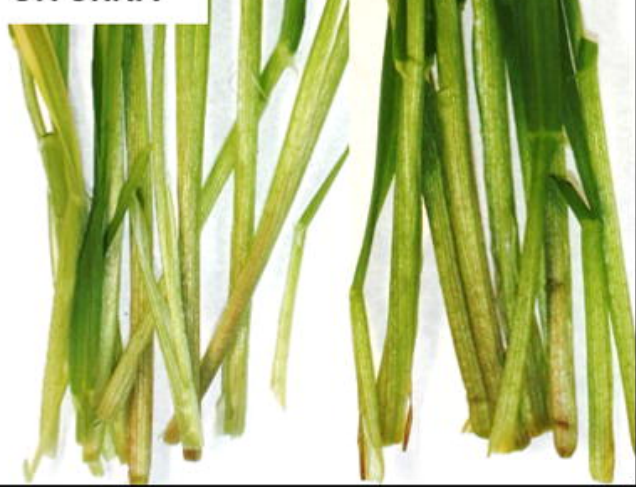


- CYP51A —CYP51B - CYP51C

1

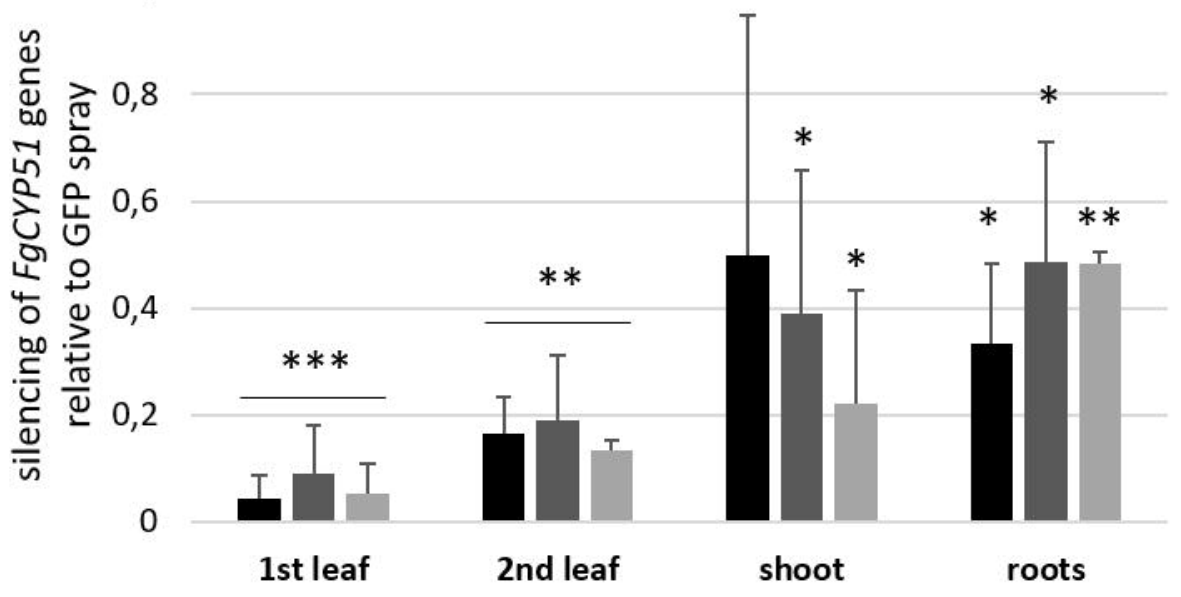


3,5

$* * *$

3,0

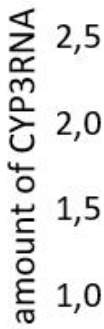

0,5

0,0

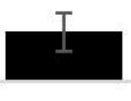

$24 h$

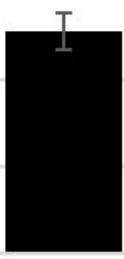

$48 \mathrm{~h}$

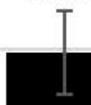


600

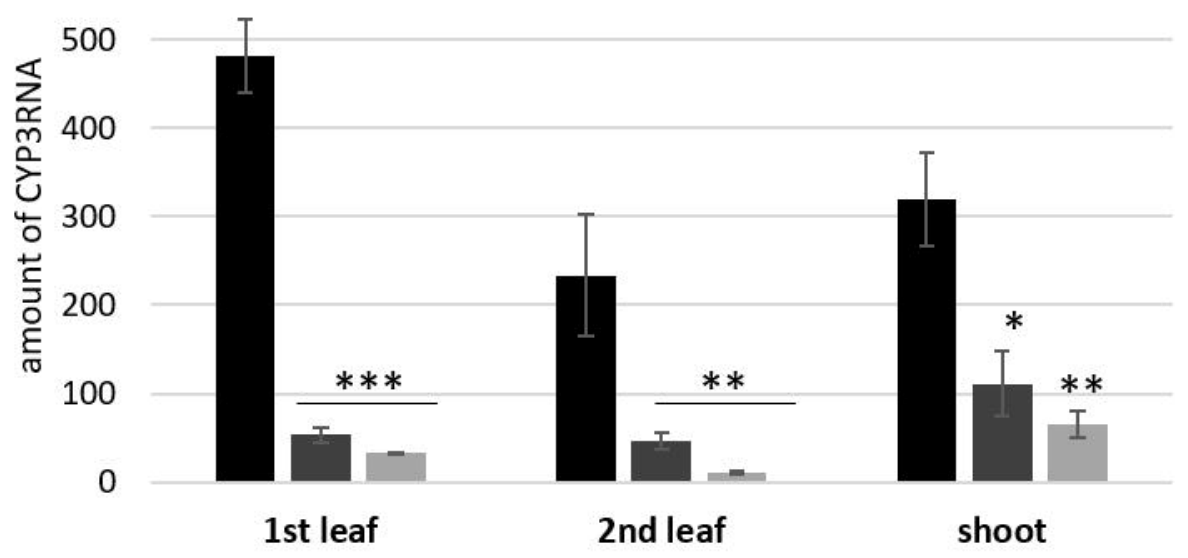

- $24 \mathrm{~h}=48 \mathrm{~h}-72 \mathrm{~h}$ 
stylet

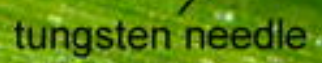

phloem sap droplet

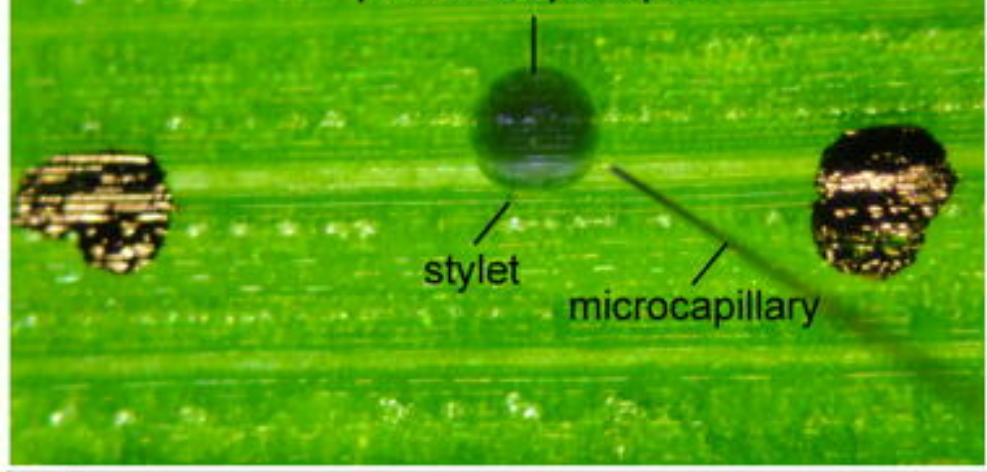

C

D

?

microcapillary

with phloem sap 
1

(1)

0,9

ذँ

है 0,7

**

으 0,6

음 0,5

ज

0,4

(1) 0,3

范 0,2

U)

$\div 0,1$

0

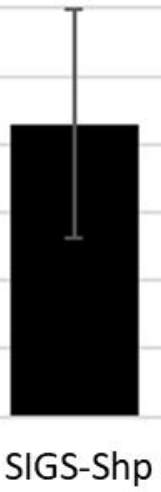

